\title{
Analisis Standarisasi Fasilitas Gedung Olahraga Universitas Negeri Yogyakarta
}

\author{
Duwi Kurnianto Pambudi \\ Fakultas Ilmu Keolahragaan, Universitas Negeri Yogyakarta \\ Jl. Colombo No. 1, Karangmalang Depok, Sleman, Yogyakarta, Indonesia \\ duwi.kp@uny.ac.id
}

\begin{abstract}
Abstrak
Penelitian ini bertujuan untuk mengetahui standarisasi ruang lingkup sebagai berikut : 1) Tipologi gedung olahraga. 2) Arena, 3) Fasilitas pengelola gedung olahraga. 4) Fasilitas Penonton pada GOR UNY sesuai dengan Permenpora No 0445 Tahun 2014. Metode yang digunakan adalah metode pendekatan analisis kualitatif dengan menggunakan teknik pengamatan langsung, studi dokumen, dan wawancara kepada pihak pengelola/ manajemen dan karyawan GOR UNY. Hasil dari penelitian ini didapatkan bahwa Tipologi untuk GOR UNY masuk dikategori Tipe A dengan beberapa kelebihan yang dimiliki GOR UNY diantaranya : Kapasitas GOR dengan 6000 tempat duduk, memiliki 30 pintu keluar GOR yang bisa mempercepat arus keluar penonton dan pemain jika terjadi hal-hal yang membahayakan/ bencana alam. Jumlah toilet yang tersedia di GOR UNY berjumlah 52 toilet yang tersebar dilantai 1,2,3. Memiliki ruangan-ruangan yang siap digunakan dalam kegiatan event dan bisa disesuaikan dengan kebutuhan/multifungsi. Tempat Parkir yang luas dan terpadu dalam satu tempat dan berada disekitar GOR dengan kapasitas parkir yang besar,mampu menampung kendaraan dalam jumlah yang banyak. Beberapa kekurangan yang ditemukan di GOR UNY adalah akses untuk difabel menuju ke tribun penonton, jumlah toilet khusus difabel.
\end{abstract}

Kata Kunci: Standarisasi, ruang lingkup, GOR UNY

\section{Standardization Analysis Facility Yogyakarta State University Sports Hall}

\section{Abstract}

This study aims to determine the standardization scope as follows: 1) Typology gymnasium. 2) Arena, 3) Facility manager gymnasium. 4) Spectator facilities in accordance with the YSU Sporthall Permenpora 0445 No. 2014. The method used is the method of qualitative analysis approach using direct observation techniques, the study of documents and interviews to the manager / management and employees YSU Sporthall. The results of this study found that the typology of YSU Sporthall sign categorized Type A with some of the advantages of YSU Sporthall include: Capacity YSU Sporthall with 6000 seating, has 30 exits YSU Sporthall which could accelerate the outflow of spectators and players when things happen that endanger / natural disasters. Number of toilets available in YSu Sporthall amounted to 52 toilets were scattered on the floor of 1,2,3. Had rooms that are ready to be used in events and activities can be tailored to the needs / multifunctional. Parking place extensive and integrated in one place and being around the YSU Sporthall with a large parking capacity, able to accommodate vehicles in large numbers. Some of the deficiencies found in YSU Sporthall is access for the disabled to get to the stands, the number of special disabled toilet.

Keywords: Standardization, scope, YSU Sporthall 


\section{PENDAHULUAN}

Fasilitas Olahraga di Universitas Negeri Yogyakarta memiliki jumlah yang sangat banyak dan bermacam-macam cabang olahraganya, sebagai contoh Kolam Renang FIK UNY, Stadion Atletik dan Sepakbola FIK UNY, Lapangan Bolabasket Outdoor, Lapangan Tenis Indoor dan Outdoor FIK UNY, Gedung Olahraga (GOR UNY). GOR UNY merupakan salah 1 fasilitas indoor yang rentan pemakaian dalam satu tahun bisa mencapai kurang lebih 50 kegiatan, baik kegiatan olahraga, dan kegiatan lain selain kegiatan olahraga.

Di Yogyakarta Gedung Olahraga lebih dari 3 gedung, akan tetapi GOR UNY menjadi salah satu tempat yang favorit untuk digunakan dalam event baik dari pihak lokal Yogyakarta, Nasional, maupun internasional. Event berskala internasional yang pernah terselenggara di GOR UNY diantara lain : Piala AFF Futsal Championship 2018, AFC Futsal CUP 2018, AFF Futsal Club Championship 2018, Event Nasional: Liga Bolabasket Indonesia, Liga Bolavoli Indonesia, PIMNAS 2018, Event Lokal DIY : Kejuaraan Bolabasket antar SMA, Kejuaraan Futsal antar SMP, Lomba Drumband. Kegiatan non olahraga yang berlangsung seperti : Pameran Buku, Konser Musik, Pameran Sains dan Teknologi, Talkshow, Job Fair, untuk internal UNY tersendiri acara rutin yang digelar di GOR UNY antara lain : Pengenalan Kehidupan Kampus Bagi Mahasiswa Baru (PKKMB) untuk mahasiswa baru UNY, Wisuda bagi mahasiswa UNY.

Undang-undang Nomor 3 Tahun 2005 tentang Sistem Keolahragaan Nasional pasal 81 mengamanatkan perlunya disusun Standar Nasional Keolahragaan. Standar $\mathrm{n}$ asional keolahragaan dimaksud meliputi : 6 (enam) standar, satu diantaranya adalah Standar Prasarana dan Sarana Olahraga. Berkenaan dengan hal itu Peraturan Pemerintah Republik Indonesia Nomor 16 Tahun 2007 Tentang Penyelenggaraan Keolahragaan pasal 89 ayat (2) menegaskan persyaratan-persyaratan yang tercakup dalam standar prasarana olahraga

Standardisasi Nasional Keolahragaan bertujuan menjamin mutu penyelenggaraan sistem keolahragaan nasional melalui pencapaian Standar Nasional Keolahragaan (Peraturan Pemerintah nomor 16 tahun 2007 Pasal 84). Peraturan Menteri Pemuda dan Olahraga Nomor 0445 Tahun 2014 pasal 1 menyatakan Standar Prasarana Olahraga Berupa Bangunan Gedung Olahraga merupakan kriteria minimal mengenai berbagai aspek yang berhubungan dengan gedung dan lingkungan sekitar gedung yang digunakan untuk kegiatan olahraga dan/atau penyelenggaraan kegiatan keolahragaan.

Pemerintah melalui Kementerian Pemuda dan Olahraga mengeluarkan Standarisasi Gedung Olahraga di Indonesia yang memiliki tujuan agar setiap fasilitas olahraga memiliki kesamaan dalam standar baik mutu maupun kriteria keselamatan dan keamanan yang dimiliki Gedung Olahraga dikarenakan dalam berolahraga akan melibatkan massa yang besar. Ruang lingkup standar menurut Permenpora No 0445 Tahun 2014 meliputi: 1) Tipologi gedung olahraga. 2) Lokasi. 3) Zona dan sirkulasi. 4) Arena. 5) Fasilitas pemain. 6) Ruang Pengelola Pertandingan/Kegiatan. 7) Fasilitas media. 8) Fasilitas pengelola gedung olahraga. 9) Fasilitas Penonton. 10) Fasilitas keselamatan dan keamanan. 11) Fasilitas komunikasi (display board). 12) Utilitas bangunan. 13) Pencegahan bahaya kebakaran. 14) Struktur dan bahan.

Dengan keterbatasan yang dimiliki maka penulis membatasi dalam penelitian ini pada ruang lingkup sebagai berikut : 1) Tipologi gedung olahraga. 2) Arena, 3) Fasilitas pengelola gedung olahraga. 4) Fasilitas Penonton pada GOR UNY. GOR UNY menjadi salah satu tempat yang sangat representative untuk digunakan sebagai kegiatan yang mengundang jumlah massa yang banyak, dengan melihat jumlah event disetiap tahunnya yang sangat banyak, dan mengacu pada standar nasional keolahragaan yang dikeluarkan oleh Kementerian Pemuda dan Olahraga Republik Indonesia yang terkait dengan penyelenggaraan olahraga yang tercakup dalam standar prasarana olahraga di GOR UNY. 


\section{METODE}

Penelitian ini menggunakan metode deskriptif kualitatif, Sugiyono (2012: 9) menyatakan bahwa penelitian kualitatif merupakan metode penelitian yang berlandaskan pada filsafat postpositivisme, digunakan untuk meneliti pada kondisi objek alamiah, dimana peneliti adalah sebagai instrumen kunci, teknik pengumpulan data dengan triangulasi, analisis data bersifat induktif atau kualitatif, dan hasil penelitian kualitatif lebih menekankan makna daripada generalisasi. Subjek penelitian adalah ruang lingkup Standar fasilitas GOR UNY dengan mengacu pada Peraturan Menteri Pemuda dan Olahraga Nomor 0445 Tahun 2014 pasal 1 menyatakan Standar Prasarana Olahraga Berupa Bangunan Gedung Olahraga. Waktu dan tempat pelaksaan penelitian adalah bulan Februari 2020 bertempat di GOR UNY. Metode penelitian menggunakan pengamatan langsung, studi dokumen, dan wawancara kepada pihak pengelola/ manajemen dan karyawan GOR UNY tentang : 1) Tipologi gedung olahraga. 2) Arena, 3) Fasilitas pengelola gedung olahraga. 4) Fasilitas Penonton pada GOR UNY

\section{HASIL DAN PEMBAHASAN}

Hasil penelitian yang dilakukan terhadap ruang lingkup standar fasilitas GOR UNY dengan mengacu pada Peraturan Menteri Pemuda dan Olahraga Nomor 0445 Tahun 2014 didapatkan hasil sebagai berikut :

1. Tipologi gedung olahraga

Tabel 1. Tipologi Gedung Olahraga

\begin{tabular}{|l|l|l|}
\hline \multicolumn{3}{|c|}{ Fungsi GOR Tipe A } \\
\hline & $\begin{array}{c}\text { Standar Sarana } \\
\text { (Permenpora 2014) }\end{array}$ & $\begin{array}{l}\text { Gedung } \\
\text { Olahraga UNY }\end{array}$ \\
\hline Bulutangkis & 4 Lapangan & 4 Lapangan \\
\hline Bolavoli & 1 Lapangan & 1 Lapangan \\
\hline Bolabasket & 1 Lapangan & 1 Lapangan \\
\hline Futsal & 1 Lapangan & 1 Lapangan \\
\hline Tenis & 1 Lapangan & - \\
\hline Lapangan & & 1 lapangan \\
\hline Senam & 1 Lapangan & 4 lapangan \\
\hline Sepak Takraw & 4 Lapangan & 64 loker \\
\hline Ruang Ganti & 20 Loker & \\
\hline
\end{tabular}

GOR UNY masuk dalam Gedung Olahraga Tipe A mengacu pada Peraturan Menteri Pemuda dan Olahraga Nomor 0445 Tahun 2014 dengan fasilitas 4 Lapangan Bulutangkis, 1 Lapangan Bolavoli, 1 Lapangan Bolabasket, 1 Lapangan Futsal, 1 lapangan Senam, 4 lapangan Sepak Takraw, memiliki 4 Ruang ganti dengan 16 loker disetiap Ruang gantinya.

Tabel 2. Ukuran Arena Gedung Olahraga

\begin{tabular}{|c|c|c|}
\hline \multicolumn{3}{|c|}{ Ukuran GOR Tipe A } \\
\hline & $\begin{array}{c}\text { Standar Sarana } \\
\text { (Permenpora 2014) }\end{array}$ & $\begin{array}{c}\text { Gedung Olahraga } \\
\text { UNY }\end{array}$ \\
\hline Panjang & $50 \mathrm{~m}$ & $50 \mathrm{~m}$ \\
\hline Lebar & $40 \mathrm{~m}$ & $35 \mathrm{~m}$ \\
\hline Tinggi & $15 \mathrm{~m}$ & $40 \mathrm{~m}$ \\
\hline
\end{tabular}

GOR UNY masuk dalam Gedung Olahraga Tipe A mengacu pada Peraturan Menteri Pemuda dan Olahraga Nomor 0445 Tahun 2014 dengan memiliki ukuran panjang arena dalam GOR 50 meter, lebar 35 meter, tinggi 40 meter. 
MEDIKORA, Vol. 19 No. 1 April 2020 - 49

Duwi Kurnianto Pambudi

Tabel 3. Kapasitas Tempat Duduk Gedung Olahraga

\begin{tabular}{|c|c|c|}
\hline \multicolumn{3}{|c|}{ Kapasitas Tempat Duduk Gedung Olahraga } \\
\hline Kapasitas GOR & $\begin{array}{c}\text { Standar Sarana } \\
\text { (Permenpora 2014) }\end{array}$ & $\begin{array}{c}\text { Gedung Olahraga } \\
\text { UNY }\end{array}$ \\
\hline Besar & Minimum 3.000 & 6000 \\
\hline Sedang & $1.000-3.000$ & \\
\hline Kecil & Maksimum 1.000 \\
\hline
\end{tabular}

GOR UNY masuk dalam Gedung Olahraga Tipe A mengacu pada Peraturan Menteri Pemuda dan Olahraga Nomor 0445 Tahun 2014 dengan kapasitas penonton 6000 tempat duduk.

2. Arena

Lantai dengan permukaan karet sintetis, kuat dan kaku, stabil, kuat dan kaku, serta tidak mengalami perubahan bentuk atau melendut.

Tabel 4.Ruang ganti pemain

\begin{tabular}{|l|l|l|}
\hline \multicolumn{3}{|c|}{ Ruang Ganti Pemain/ Atlet GOR Tipe A } \\
\hline & $\begin{array}{c}\text { Standar Sarana } \\
\text { (Permenpora 2014) }\end{array}$ & $\begin{array}{c}\text { Gedung Olahraga } \\
\text { UNY }\end{array}$ \\
\hline Ruang Ganti Pemain & Minimum 2 unit & 4 unit \\
\hline Toilet & Minimum 2 unit & 8 unit \\
\hline Washtafel & Minimum 2 unit & 8 unit \\
\hline Cermin & Minimum 2 unit & 8 unit \\
\hline $\begin{array}{l}\text { Ruang Bilas dengan air } \\
\text { panas }\end{array}$ & minimum 4 unit & 24 unit \\
\hline
\end{tabular}

GOR UNY masuk dalam Gedung Olahraga Tipe A mengacu pada Peraturan Menteri Pemuda dan Olahraga Nomor 0445 Tahun 2014 dengan memiliki Ruang Ganti Pemain sejumlah 4 unit, Toilet 8 unit,Washtafel 8 unit, Cermin 8 unit, Ruang Bilas dengan air panas 24 unit dan semua melebihi dari batas minimum yang disyaratkan.

Tabel 5. Ruang Ganti Pelatih dan Wasit

\begin{tabular}{|l|l|l|}
\hline \multicolumn{3}{|c|}{ Ruang Ganti Pelatih dan Wasit GOR Tipe A } \\
\hline & $\begin{array}{c}\text { Standar Sarana } \\
\text { (Permenpora 2014) }\end{array}$ & $\begin{array}{c}\text { Gedung Olahraga } \\
\text { UNY }\end{array}$ \\
\hline Ruang Ganti Pelatih & 2 unit & 4 unit \\
\hline Ruang Ganti Wasit & 1 Unit & 2 Unit \\
\hline
\end{tabular}

GOR UNY masuk dalam Gedung Olahraga Tipe A mengacu pada Peraturan Menteri Pemuda dan Olahraga Nomor 0445 Tahun 2014 dengan memiliki Ruang Ganti Pelatih 4 unit, Ruang Ganti Wasit 2 Unit.

Ruang Massage dan Fisioterapi

Belum ada ruang khusu fisioterapi, tetapi apabila dibutuhkan bisa menggunakan ruangan serbaguna 1 atau 2 
MEDIKORA, Vol. 19 No. 1 April 2020 - 50

Duwi Kurnianto Pambudi

Tabel 6. Ruang Medis

\begin{tabular}{|l|l|l|}
\hline \multicolumn{3}{|c|}{ Ruang Medis Tipe A } \\
\hline & $\begin{array}{c}\text { Standar Sarana } \\
\text { (Permenpora 2014) }\end{array}$ & $\begin{array}{c}\text { Gedung Olahraga } \\
\text { UNY }\end{array}$ \\
\hline Luas Minimum & $18 \mathrm{~m} 2$ & $18 \mathrm{~m}^{2}$ \\
\hline $\begin{array}{l}\text { Tempat Tidur untuk pemeriksaan } \\
\text { dan perawatan sementara }\end{array}$ & $2 \mathrm{Buah}$ & 1 buah \\
\hline Washtafel & $1 \mathrm{Buah}$ & 1 wastafel \\
\hline Closet & 1 Buah & 2 kamar mandi \\
\hline Bisa diakses oleh diffable & & bisa, letak di lantai \\
1
\end{tabular}

GOR UNY masuk dalam Gedung Olahraga Tipe A mengacu pada Peraturan Menteri Pemuda dan Olahraga Nomor 0445 Tahun 2014 dengan memiliki Ruang Medis dengan Luas Minimum18 m2 tempat tidur untuk pemeriksaan dan perawatan sementara 1 buah Washtafel 1 Buah, Closet 2 kamar mandi, Bisa diakses oleh diffable bisa, letak di lantai 1. Ruang Tes Doping

Belum ada ruang spesifik untuk tes dopping, tetapi apabila memerlukan ruangan yang bisa digunakan untuk tes dopping GOR UNY memiliki alternatif ruangan yang bisa digunakan untuk dibuat tes dopping.

Ruang Pemanasan

Setiap ruang ganti pemain bisa digunakan sebagai tempat pemanasan dengan ukuran $63 \mathrm{~m} 2$.

Ruang Latihan Beban

Fitness di GOR UNY sudah terintegrasi dengan Health And Sport Centre (HSC) FIK UNY.

Ruang Rehat Pemain

Ruang ganti memungkinkan juga bisa digunakan sebagai tempat untuk istirahat dan membersihkan diri setelah pertandingan,

Nama Ruang dan Sistem Tanda

Masing-masing ruangan di GOR sudah diberikan tanda untuk nama dan fungsi ruang, tulisan cukup jelas dan mudah dibaca.

Tabel 7. Fasilitas pengelola gedung olahraga.

\begin{tabular}{|c|c|c|}
\hline Nama Ruang & \multicolumn{2}{|l|}{ Ruangan di GOR UNY } \\
\hline Ruang Manajer & \multirow{2}{*}{\multicolumn{2}{|c|}{$\frac{\text { Ruang Manajemen } \quad \text { ukuran } 35 \mathrm{~m}^{2}}{900 \times 700 \text { (menogunakan ruang ranat) }}$}} \\
\hline Ruang Sekretariat & & $9.00 \times 7.00$ (menggunakan ruang rapat) \\
\hline Ruang Pengawas Pertandingan & \multicolumn{2}{|l|}{1 ruangan official } \\
\hline Ruang Wasit & \multicolumn{2}{|l|}{1 ruangan official } \\
\hline Ruang Serbaguna/ Ruang Rapat & $\begin{array}{l}\text { Lobi Utama ukuran } 11 \mathrm{~m} \text { x } 6 \mathrm{~m} \\
\text { Ruang Kuliah } 1 \text { (GOR Sayap Barat) } \\
7.00 \mathrm{~m} \\
\text { Ruang Kuliah } 2 \text { (GOR Sayap Timur) } \\
7.00 \mathrm{~m}\end{array}$ & $\begin{array}{l}12.00 \mathrm{~m} \mathrm{x} \\
9.00 \mathrm{~m} \mathrm{x}\end{array}$ \\
\hline Gudang Perlengkapan & \multicolumn{2}{|c|}{$\begin{array}{l}\text { Memiliki } 4 \text { Gudang Perlengkapan, } 1 \text { dilantai } 1 \text { dan } \\
3 \text { dilantai } 2\end{array}$} \\
\hline
\end{tabular}

GOR UNY masuk dalam Gedung Olahraga Tipe A mengacu pada Peraturan Menteri Pemuda dan Olahraga Nomor 0445 Tahun 2014 dengan memiliki Fasilitas Pengelola Gedung Olahraga sebagai berikut : Ruang Manajemen ukuran 35m2, Ruang Sekretariat $9.00 \times 7.00$ (menggunakan ruang rapat), Ruang Pengawas Pertandingan 1 ruangan official, Ruang Wasit 1 ruangan official, Ruang Serbaguna/ Ruang Rapat Lobi Utama ukuran $11 \mathrm{~m}$ 
x 6 m, Ruang Kuliah 1 (GOR Sayap Barat) 12.00 m x 7.00 m, Ruang Kuliah 2 (GOR Sayap Timur) $9.00 \mathrm{~m}$ x $7.00 \mathrm{~m}$. Gudang Perlengkapan Memiliki 4 Gudang Perlengkapan, 1 dilantai 1 dan 3 dilantai 2.

3. Fasilitas Penonton

Tabel 8. Fasilitas VIP

\begin{tabular}{|l|l|}
\hline \multicolumn{1}{|c|}{ Nama } & \multicolumn{1}{c|}{ Fasilitas GOR UNY } \\
\hline $\begin{array}{l}\text { Akses Khusus VIP } \\
\text { Lobby VIP }\end{array}$ & memilki akses masuk khusus untuk VIP \\
\hline Toilet VIP & 1 toilet di VIP \\
\hline Tribun VIP & bisa menampung 20 tamu VIP \\
\hline Fasilitas Ibadah & $\begin{array}{l}\text { tidak ada fasilitas khusus tetapi ruangan } \\
\text { besar dan bisa digunakan untuk ibadah, } \\
\text { ukuran ruang VIP 9 m x 7 m }\end{array}$ \\
\hline
\end{tabular}

GOR UNY masuk dalam Gedung Olahraga Tipe A mengacu pada Peraturan Menteri Pemuda dan Olahraga Nomor 0445 Tahun 2014 dengan memiliki Fasilitas VIP sebagai berikut: Akses Khusus VIP Lobby VIP memilki akses masuk khusus untuk VIP, Toilet VIP 1 toilet di VIP, Tribun VIP bisa menampung 20 tamu VIP, Fasilitas Ibadah tidak ada fasilitas khusus tetapi ruangan besar dan bisa digunakan untuk ibadah, ukuran ruang VIP 9 $\mathrm{m} \times 7 \mathrm{~m}$.

Tabel 9. Penonton Umum

\begin{tabular}{|l|l|}
\hline \multicolumn{1}{|c|}{ Nama } & \multicolumn{1}{c|}{ Fasilitas GOR UNY } \\
\hline Jumlah pintu masuk & $\begin{array}{l}\text { 30 pintu yang terbagi menjadi } 6 \text { pintu di } \\
\text { lantai 1, 11 pintu dilantai 2, 14 pintu di lantai } \\
3\end{array}$ \\
\hline Selasar/Koridor & $\begin{array}{l}\text { 4 selasar yaitu selasar GOR sayap timur, } \\
\text { selatan, barat, utara }\end{array}$ \\
\hline Tribun Penonton & 6000 tempat duduk \\
\hline Fasilitas Ibadah & 1 mushola dengan \\
\hline Kantin & menjual minuman ringan \\
\hline
\end{tabular}

GOR UNY masuk dalam Gedung Olahraga Tipe A mengacu pada Peraturan Menteri Pemuda dan Olahraga Nomor 0445 Tahun 2014 dengan memiliki Fasilitas untuk penonton umum sebagai berikut : Jumlah pintu masuk 30 pintu yang terbagi menjadi 6 pintu di lantai 1, 11 pintu dilantai 2, 14 pintu di lantai 3, Selasar/Koridor 4 selasar yaitu selasar GOR sayap timur, selatan, barat, utara, Tribun Penonton 6000 tempat duduk, Fasilitas Ibadah 1 mushola dengan, Kantin menjual minuman ringan. Kekurangan yang ditemukan adalah akses untuk difabel apabila ingin menonton di tribun penonton umum akan mengalami kesusahan dikarnakan semua akses ke tribun menggunakan tangga, perlu adanya perhatian khusus untuk akses difabel tersebut agar bisa menonton di tribun umum.

Tabel 10. Toilet Penonton

\begin{tabular}{|l|l|l|}
\hline \multicolumn{3}{|c|}{ Toilet Penonton } \\
\hline & \multicolumn{1}{|c|}{$\begin{array}{c}\text { Standar Sarana } \\
\text { (Permenpora 2014) }\end{array}$} & \multicolumn{1}{|c|}{ Gedung Olahraga UNY } \\
\hline Toilet Pria & $\begin{array}{l}\text { 1 WC : 200 penonton } \\
\text { pria }\end{array}$ & 13 toilet dengan 2 KM total \\
& $\begin{array}{l}\text { W } \\
\text { Toilet Wanita } \\
\text { wanita }\end{array}$ & $\begin{array}{l}8 \text { toilet dengen 2 KM total } \\
16\end{array}$ \\
\hline
\end{tabular}


GOR UNY masuk dalam Gedung Olahraga Tipe A mengacu pada Peraturan Menteri Pemuda dan Olahraga Nomor 0445 Tahun 2014 dengan memiliki Toilet untuk penonton dengan perbandingan sebagai berikut : dari 6000 kapasitas dengan jumlah 52 toilet maka perbandingan yang didapatkan adalah $6000: 52=116$ orang untuk 1 Toilet, tetapi yang perlu menjadi perhatian adalah toilet yang digunakan khusus untuk difabel, perlu ditambahkan sebagai salah satu fasilitas yang dimilikioleh GOR UNY.

Nilai tambah yang sangat mendukung GOR UNY sebagai salah satu fasilitas olahraga yang bisa digunakan untuk massa dalam jumlah yang besar adalah fasilitas parkir kendaraan bermotor yang sangat luas, dari hasil pengamatan yang dilakukan tempat parkir di GOR UNY memiliki tempat Parkir yang berada di sekeliling GOR UNY dengan kapasitas kurang kebih 200an mobil dan 3000an motor.

\section{SIMPULAN}

Dari hasil penelitian yang telah dipaparkan maka dapat ditarik kesimpulan sebagai beriktDengan keterbatasan yang dimiliki maka penulis membatasi dalam penelitian ini pada ruang lingkup sebagai : GOR UNY masuk kategori Tipe A sesuai dengan Peraturan Menteri Pemuda dan Olahraga Nomor 0445 Tahun 2014. Kelebihan GOR UNY diantaranya : Kapasitas Penonton dengan 6000 tempat duduk, ruangan-ruangan yang ada di GOR UNY dan fasilitas yang di dalamnya sangat mendukung untuk melakukan kegiatan yang memerlukan ruangan dalam jumlah yang banyak dan ukuran besar, jumlah toilet yang banyak, serta fasilitas parkir kendaraan yang sangat luas dan terpusat menjadikan GOR UNY memiliki nilai lebih dalam penyediaan fasilitas olahraga. Kekurangan yang ditemukan di GOR UNY diantaranya : akses penonton difabel menuju ke tribun penonton umum belum bisa memudahkan bagi orang difabel. Toilet khusus yang disedikan untuk penonton difabel.

\section{DAFTAR PUSTAKA}

Kristiyanto, A. (2012). Pembangunan Olahraga Untuk Kesejahteraan Rakyat dan Kejayaan Bangsa. Surakarta : Yuma Pustaka

Presiden .(2007). Peraturan Pemerintah RI Nomor 16, Tahun 2007, tentang Penyelenggaraan Keolahragaan

Presiden .(2007). Peraturan Pemerintah RI Nomor 17, Tahun 2007, tentang Penyelenggaraan Pekan dan Kejuaraan Olahraga

Permenpora 2014 No. 0445, Standar Prasarana Olahraga Berupa Bangunan Gedung Olahraga

Republik Indonesia .(2002). Undang-Undang RI Nomor 28, Tahun 2002, tentang Bangunan Gedung

Republik Indonesia .(2005). Undang-Undang RI Nomor 3, Tahun 2005, tentang Sistem Keolahragaan Nasional

Sugiyono. (2012) Metode penelitian pendidikan pendekatan kuantitatif, kualitatif, dan $R \& D$. Bandung: Alfabeta. 